\title{
La novela intrahistórica: entre la postmemoria y la pophistoria
}

\begin{abstract}
Resumen:
Este estudio comparativo tiene en cuenta dos obras escritas por mujeres: El violín de Auschwitz (1994) de Maria Àngels Anglada y La Tabla Esmeralda (2012) de Carla Montero. Ambas novelas, a pesar de sus casi veinte años de distancia, ofrecen una serie de rasgos comunes. Su referente extraliterario se sitúa en el mismo campo temático (el nazismo, la deportación y el Holocausto), ambas emplean la misma modalidad narrativa (el presente de la narración intradiegética y homodiegética engloba otra narración, extradiegética y heterodiegética, para relatar los hechos del pasado) y ambas ofrecen una visión desde abajo, protagonizada por los personajes ficcionales - lo que permite suponer que las dos novelas pertenecen a un subgénero de la novela intrahistórica.
\end{abstract}

Palabras clave: novela histórica, novela intrahistórica, postmemoria, pophistoria

\section{Abstract:}

\section{Intrahistorical Novel between Postmemory and Pophistory}

This comparative study takes into account two books written by women: El violin de Auschwitz (1994) by Maria Àngels Anglada and La Tabla Esmeralda (2012) by Carla Montero. Both novels, despite almost twenty years between them, offer a series of common features. Their extraliterary referent falls into the same thematic 
field (Nazism, deportation and the Holocaust); both employ the same narrative modality (the presenceof the intradiegetic and homodiegetic narration includes another narration, extradiegetic and heterodiegetic, about the past); last but not least, both titles offer a 'view from below', carried out by fictional characters - which allows to suppose that the two novels belong to a subcategory of the intrahistoric novel.

Keywords: Historical Novel, Intrahistorical Novel, Postmemory, Pophistory

La literatura light, como el cine light y el arte light, da la impresión cómoda al lector, y al espectador, de ser culto, revolucionario, moderno, y de estar a la vanguardia, con el mínimo esfuerzo intelectual. De este modo, esa cultura que se pretende avanzada y rupturista, en verdad propaga el conformismo a través de sus manifestaciones peores: la complacencia y la autosatisfacción.

(Vargas Llosa, 2009: 7)

Para acercarnos al fenómeno de la novela intrahistórica, sería útil distinguir primero tres grandes líneas en la tradición de la novela histórica, según el uso que se hace de los materiales históricos (Fernández Prieto, 2006: 171-176). Para empezar, la novela histórica tradicional con una narración omnisciente en tercera persona arranca del romanticismo y continúa en la novela histórica realista. El "efecto de historia" deseado se obtiene combinando la verosimilitud y el didacticismo con el respeto hacia la base documental de la novela y el control de los anacronismos. Mientras tanto, la novela histórica moderna mantiene el respeto hacia los datos históricos básicos, pero los maneja con una perspectiva muy distante de la tradicional. La subjetivización de la historia permite trasmitir el pasado desde la interioridad de los personajes o desde el filtro moral e ideológico del narrador. Las visiones parciales y subjetivas se expresan mediante opciones modalizadoras 
en primera persona o con una focalización selectiva en uno o varios personajes - lo que, entre otros efectos, provoca la disolución de la objetividad autorial y de las fronteras temporales entre el pasado de la historia y el presente enunciativo. Finalmente, a partir de la segunda mitad del siglo XX, la llamada nueva novela histórica o la novela histórica posmoderna propone un modelo genérico en una abierta ruptura con las normas básicas de la novela histórica tradicional, mediante la propuesta de historias alternativas, apócrifas o contrafácticas sobre sucesos o personajes de gran relevancia histórica, la exhibición de procedimientos metaficcionales e hipertextuales paródicos o satíricos, y la multiplicación de los anacronismos cuyo objetivo es desmontar el orden cronológico supuestamente natural de la historiografía.

Cabe subrayar, siguiendo a Elisabeth Wesseling (1991: 155-190), que los autores contemporáneos no distorsionan la historia establecida por mero capricho, ni juegan irresponsablemente a confundir lo histórico y lo ficcional, sino que tratan de inventar historias alternativas que puedan compensar los más graves defectos de la historia occidental: el etnocentrismo, el androcentrismo y el imperialismo. Mientras tanto, las llamadas "metaficciones historiográficas" (Hutcheon, 1989: 3-32) neutralizan la consagrada oposición entre representación histórica y representación ficcional, exhiben una intensa autoconciencia acerca de la naturaleza discursiva e intertextual del pasado y de los hechos históricos, construidos como tales por la misma narración (Barthes, 1967: 163-17), y finalmente cuestionan la capacidad del discurso histórico para ofrecer una versión fidedigna de lo que ocurrió en el pasado. A este esquema de división tripartita de la novela histórica contemporánea esbozado más arriba se le pueden añadir otras categorías o subcategorías, inspiradas tanto en los estudios feministas como en los trabajos sociológicos y psicológicos más recientes. Las tendencias a reincorporar las voces marginalizadas en un discurso sobre el pasado y a integrar las perspectivas a nivel microhistórico van acompañadas por un cambio generacional. El panorama del género se enriquece con las voces pertenecientes a la nueva narrativa femenina en primera persona, lo que en el campo que aquí nos interesa nos lleva a su vez a una noción de novela intrahistórica. 
El término "intrahistoria", cuya paternidad corresponde indudablemente a Miguel de Unamuno (1895), después de verse resemantizado a la hora de los avances de la llamada microstoria italiana, ha sido apropiado y redefinido por toda una generación de investigadoras que no vacilaban en incorporar en sus estudios una óptica feminista. Lo emplean Biruté Ciplijauskaité (1988), Gloria da Cuhna-Giabbai (1994), María del Carmen Boves Naves (1995) y Luz Marina Rivas (2000) para caracterizar a las novelas que recrean el pasado desde una perspectiva intimista, ajena al ejercicio del poder y a los grandes acontecimientos históricos, políticos y militares. Cabe subrayar que la entrada en la escena literaria de las mujeres escritoras, hasta entonces ausentes en el campo de la novela histórica, coincide perfectamente con una nueva escuela de mujeres historiadoras, quienes prestan interés a figuras carismáticas del pasado (no necesariamente femeninas, aunque sí en muchos casos) hundidas en el olvido. Así, por ejemplo, los estudios históricos bien documentados inspiraron narraciones literarias y terminaron por rescatar del olvido a grandes mujeres artistas como Artemisia Gentilleschi o Camille Claudel.

Biruté Ciplijauskaité, quien ha dedicado todo un capítulo de su libro sobre la novela femenina contemporánea a la novela histórica, subraya no solamente el aspecto innovador de la narrativa femenina, su subjetividad e insistencia en el elemento afectivo, sino la relación que une estas novelas de mujeres con las nuevas tendencias historiográficas:

Muchas de las autoras jóvenes insisten en el elemento afectivo, en una visión que no deje de ser personal. En esto coinciden con la revolución general de la historiografía; hoy se prefiere fijarse no en los grandes acontecimientos y las figuras destacadas, contando las victorias y las derrotas, las leyes y sus infracciones, como se solía hacer en los siglos anteriores, sino en lo que Unamuno ha denominado la "intrahistoria". [...] Se trata de una presentación de ambientes de gestación más bien que de acción precipitada. (Ciplijauskaité, 1988: 124-125)

Ya desde los años 70 del siglo XX, la atención de los historiadores profesionales se ha desplazado progresivamente desde la llamada 
"historia de los acontecimientos" (histoire événementielle) hasta la historia de larga duración, historia de las mentalidades, historia de las minorías, sin olvidar por lo tanto la reflexión sobre la construcción misma del discurso historiográfico. En este panorama se hizo entender igualmente la voz de la llamada "microhistoria" o "historia desde abajo", cuyos partidarios argumentaban que partiendo de un detalle marginalizado por los archivos históricos es posible reconstruir un cuadro complejo y completo en cuanto a la época y su mentalidad. Un paso más y nos encontramos en la frontera entre la disciplina historiográfica y la creación literaria, y un texto que reescribe la historia de los personajes anónimos y de sus vidas privadas torcidas por la historia colectiva puede con toda legitimidad ser clasificado como un subtipo de novela histórica: la llamada novela intrahistórica. Luz Marina Rivas nos ofrece una definición aproximativa y, sin embargo, pertinente, insistiendo en la transmisión generacional del bagaje histórico:

Podemos acercarnos a conceptualizar la novela intrahistórica como la narración ficcional de la historia desde la perspectiva de los subalternos sociales, que, aunque víctimas de la misma, no son sus agentes pasivos; tienen un bagaje histórico por vía de la tradición entendida con vínculo entre pasado y presente dado por la costumbre y los modos culturales trasmitidos generacionalmente. [...] La intrahistoria es, por lo tanto, una visión de la historia desde los márgenes del poder y tiene como protagonistas a personajes cuya tensión entre espacio de experiencia o habitus y horizonte de espera resulta en una conciencia del subalterno de un pasado y de un futuro muy distantes a los de la historia oficial. (Rivas, 2000: 58)

Las novelas intrahistóricas, muchas veces escritas por mujeres, se basan en la materia histórica alimentada tanto por la política y las guerras como por lo cotidiano y lo doméstico, y ofrecen al lector la posibilidad de una búsqueda de la identidad individual y colectiva, desde una perspectiva cargada de componentes afectivos, lenguajes y formas de la cultura popular y memoria popular. Las novelas de este tipo abundan en la generación de la postmemoria (Hirsch, 2008: 103138) que accede al palimpsesto del pasado en su dimensión afectiva, a través del lenguaje, de los testimonios de familiares, del discurso 
historiográfico en un interesante proceso de lectura y relectura, intertextualidad y traducción, y una constante interrogación sobre la naturaleza del original y el artificio, la realidad y la ficción, la historia y el mito, la memoria y el olvido. Las novelas históricas nos abren entonces una vía de reflexión sobre los acontecimientos traumáticos de nuestras sociedades contemporáneas: la guerra civil española, el nazismo, el Holocausto, las dictaduras del siglo XX, desplegando un abanico de estrategias (Cichocka, 2016).

Después de este preámbulo necesario, sería provechoso esbozar un estudio comparativo, teniendo en cuenta dos obras escritas por mujeres: El violín de Auschwitz (1994) de Maria Àngels Anglada (título original en catalán: El violí d'Auschwitz) y La Tabla Esmeralda (2012) de Carla Montero. Ambas novelas, a pesar de sus casi veinte años de distancia, ofrecen rasgos comunes. Su referente extraliterario se sitúa en el mismo campo temático (el nazismo, la deportación y el Holocausto), ambas emplean la misma modalidad narrativa (el presente de la narración intradiegética y homodiegética engloba otra narración, extradiegética y heterodiegética, para relatar los hechos del pasado) y ambas ofrecen una visión desde abajo, protagonizada por los personajes ficcionales que, en los márgenes de la Historia, encarnan el sufrimiento del pueblo judío: Daniel, un luthier judío de Cracovia, deportado a Auschwitz; y Sarah Bauer, hija de una familia judía de Alsacia expoliada por los nazis. Además, en ambos casos, se trata de unos verdaderos éxitos literarios.

Sin embargo, aquí es donde terminan las similitudes. Maria Àngels Anglada (1930-1990) fue poeta, escritora, filóloga y crítica literaria de renombre, y su novela sobre un músico judío en el campo de exterminio es considerada como una obra sumamente seria. Está inscrita en la lista , al lado de Primo Levi o Jorge Semprún, de la llamada Biblioteca de la Deportación, cuyo catálogo digital (véase la bibliografía para el enlace) abarca unos dos mil títulos y sigue creciendo. Mientras tanto, la madrileña Carla Montero (nacida en 1973) corresponde a una imagen mediática de una escritora de éxito que no vacila en atribuir a sus novelas un género literario bautizado como "novela coctelera", lo que realmente disminuye sus posibilidades para ser tomada en serio por la 
crítica literaria. Sin embargo, esta mezcla estilística es precisamente uno de los rasgos característicos de la novela histórica contemporánea. En cuanto a la narración de la historia colectiva desde lo privado, llevada a cabo desde una perspectiva adoptada por los personajes ficcionales, pero representativos de una comunidad silenciada, estos indicios suelen combinarse en el marco de la llamada novela intrahistórica, género favorecido precisamente por las mujeres escritoras.

Si mi hipótesis es correcta, El violín de Auschwitz y La Tabla Esmeralda comparten rasgos de novelas intrahistóricas, se basan en la materia histórica alimentada tanto por la política como por lo cotidiano, y ofrecen una revisión de la historia desde los márgenes del poder, desde una perspectiva cargada de componentes afectivos. En el contexto de la Península Ibérica, esta revisión de la historia se vuelve urgente: lo prueba la olvidada lista de seis mil judíos españoles, preparada bajo el régimen de Franco para ser, presumiblemente, entregada a Himmler (Garzón, 1997), pero borrada de los archivos por las autoridades franquistas como todos los indicios de su actitud antisemita y cualquier colaboración en el Holocausto (Reverte, 2010).

\section{Desde la novela intrahistórica a la pophistoria: $E l$ violín de Auschwitz}

La novela de Maria Àngels Anglada se abre con tres elementos paratextuales: una dedicatoria, palabras de reconocimiento (p. 9) y una nota (p. 10). En la breve dedicatoria encontramos dos versos solamente: "A las víctimas / En memoriam" (p. 7). En las palabras de reconocimiento (p. 9) "La autora expresa su gratitud al luthier Ramon Pinto i Comas" [ortografía original]. Y en la nota (p. 10) leemos una promesa de rigurosidad:

Los documentos que encabezan los capítulos son auténticos. Cfr.: Reimund Schnabel, Macht ohne Moral [Texte imprimé], eine Dokumentation über die SS, Röderber-Verlag, Frankfurt, 1957 [Traducción al castellano: Poder sin moral. Historia de las SS, Seix Barral, Barcelona, 1966]. 
La narración extra- y heterodiegética que predomina en la novela empieza in medias res: Daniel, el protagonista, sale de la celda de arresto, después de cuatro días. Su delito: haberse dormido y no salir puntualmente después del toque de diana. Resulta que Daniel se encuentra preso en "El Drezflusselager —el Campo de los Tres Ríos" que, en realidad, no se encuentra en ninguna de las fuentes consultadas, salvo en las reseñas de El violín de Auschwitz. Es un detalle interesante para una novela que quiere ser histórica, escrita por una filóloga de renombre y basada en "los documentos auténticos."

Si Daniel, el protagonista, es un personaje ficticio, su mayor enemigo y opresor, "Sauckel, el comandante, aquel gigante sádico y refinado" tiene el apellido de Fritz Sauckel (1894-1946), un destacado político nazi, detenido por las autoridades aliadas, quien fue uno de los doce condenados a muerte durante los juicios de Núremberg; pero esta coincidencia tampoco tiene demasiada importancia para el desarrollo de la intriga. Lo que más importa es la ficción literaria: al entrar al campo Daniel miente declarando que su oficio es "carpintero, ebanista”. Sin embargo, es más que carpintero: es luthier. Y, para ser un joven luthier judío de Cracovia, está muy al corriente de todo lo que ocurre en su país bajo la ocupación alemana, y también al corriente de todo lo que toca al "destino de su pueblo":

Conocía demasiado bien a los que hilaban el destino de su pueblo: aquella especie de asesinos, aquellos oficiales de las Waffen-SS, monstruos disfrazados con uniformes impecables, cuando no estaban salpicados de sangre, bien peinados, con frecuencia hombres de cultura [...]. Para estos goyim [...] no existía el antiguo mandamiento de "no matarás". (pp. 29-30)

El tono de este fragmento es representativo de toda la novela : para una supuesta novela intrahistórica, no se trata de ninguna relectura del pasado. La visión de un campo de concentración es totalmente esquemática: los monstruos en uniformes frente a las víctimas indefensas, personificadas por Daniel y sus amigos del campo. Sin embargo, para estar tan al corriente del destino del pueblo judío, un luthier de Cracovia necesitaría el don de clarividencia, o una conciencia contemporánea de la historia del Holocausto, que posee sin duda la autora de la 
novela, pero que resulta inimaginable en un joven judío de los años 40 . Por otra parte, a la autora misma le cuesta disciplinar su imaginación y subordinar su relato a una lógica de los hechos históricos, en mera relación con la historia del gueto de Cracovia. Cuando leemos que "al cabo de meses, largos como años, tan llenos de dolor, Daniel dudaba ya de todo" (p. 30), deberíamos preguntarnos cuándo empezó la deportación del gueto de Cracovia (fue el 30 de mayo de 1942), cuándo tuvo lugar la liquidación del gueto (el 13-14 de marzo de 1943), si el destino era Auschwitz (y no lo era: al principio los transportes se dirigieron a Płaszów y a Bełżec; luego a Płaszów para los judíos aptos para trabajar y a Auschwitz, finalmente, para los transportes cuyo destino era la muerte). Resulta, pues, que para un judío precisamente de Cracovia sería poco probable sobrevivir "unos meses" en el campo de exterminio de Auschwitz. Como subraya Katy Hazan en su ensayo sobre los lugares del olvido (la traducción al castellano es mía):

Un $80 \%$ de los judíos no entraba en el campo. Hasta el mes de mayo de 1944 la selección tenía lugar en el exterior, en la Judenrampe, entre ambos campos (I y II), en la prolongación de la estación de trenes. Hoy en día completamente abandonada, es confundida con la rampa construida en el 1944, para la llegada de los judíos de Hungría. (Hazan, 2005: 261)

Hablando de una selección en la rampa, en la novela se oyen "los gritos desesperados y ahogados" (p. 80). La frase "No los han matado a tiros" sugiere el uso de los "camiones de la muerte" (p. 81), lo que es un anacronismo, porque en la página siguiente "ya se sabía en el lager que muchos habían escogido el camino de la rebelión y la muerte, resistiendo en el gueto de Varsovia" (p. 82). En realidad, la insurrección del gueto empezó el 19 de abril de 1943 . Y en aquel momento ya nadie se servía de los camiones de gas: las ejecuciones masivas con Zyklon B empezaron en Auschwitz en 1941 (en septiembre fueron ejecutadas 900 personas al mismo tiempo). En cambio, los camiones de la muerte, inventados por los soviéticos de la NKVD, fueron utilizados por los miembros de los Einsatzgruppen en el Este a principios de la Segunda Guerra Mundial. Por si fuera poco, para los judíos de Cracovia el primer paso por la cámara de gas tuvo lugar precisamente el 13 de marzo 
de 1943: las víctimas fueron los 1492 judíos del gueto de Cracovia. Lo que significa que un judío de Cracovia en uno de los campos de Auschwitz tenía pocas posibilidades de mantenerse vivo y estar en condiciones de conocer el trágico destino de su pueblo, a no ser que se tratase de algún miembro del Sonderkomando que participara en los trabajos de exterminio. Al lado de todos estos errores históricos, los errores ortográficos parecen anodinos: "el Ryneck Głowny" en vez de Rynek Główny (p. 15), "Mathaeus Dobrucky" en vez de Mateusz Dobrucki (p. 16), "Wienasky" en vez de Wieniawski (p. 17), etc.

En resumidas cuentas, para cualquier lector con un buen conocimiento de la historia del Holocausto, la lectura de El violín de Auschwitz será por lo menos problemática, mientras que un lector con menos conocimiento y más curiosidad no va a aprender nada más que una visión estereotipada y sesgada de los hechos. Y es una lástima, porque para un escritor en busca de inspiración sobre aquella época trágica, los monumentales estudios históricos - empezando por The Destruction of the European Jews (1961) de Raul Hilberg - se entremezclan con testimonios de supervivientes, como $Z$ Auszwicu do Belsen. Przygody (2000) del escritor polaco emigrado a Bruselas, el profesor Marian Pankowski (1919-2011); incluyendo también los relatos sobre las orquestas de los campos, como los de Fania Fénelon (Sursis pour l'orchestre, 1976), Szymon Laks (Gry oświęcimskie, 1976, traducido al francés, inglés y español) o Jacques Stroumsa (Tu choisiras la vie: violoniste à Auschwitz, 1998). Sus testimonios demuestran invariablemente que aquella realidad era infinitamente más compleja de lo que nos imaginamos hoy.

\section{Desde la pophistoria a la novela pophistórica: La Tabla Esmeralda}

Después de comprobar que la supuesta novela intrahistórica de Maria Ángels Anglada, bien documentada y basada en una serie de fuentes históricas, no ofrece a sus lectores nada más que una colección de estereotipos y de lugares comunes, sería poco probable que la llamada "novela coctelera" de Carla Montero nos ofreciera otra cosa que una 
serie de clichés. En efecto, la autora madrileña no hace sino aplicar a la letra la receta de Umberto Eco, sabiendo que Eco llegó a más gente con El nombre de la rosa (1980), una opera aperta con varios niveles de lectura, mezclando elementos históricos, filosóficos, policíacos y eróticos, que con sus ensayos científicos. Hablando de las modas literarias, 30 años después Carla Montero recuerda una anécdota sobre "la coctelera de Umberto Eco":

un poco de intriga, un poco de sexo, un poco de violencia, una ambientación histórica... y jvoilá!: como por arte de magia, sacamos un "bestseller" de la coctelera. Si El nombre de la rosa triunfó, no fue únicamente porque Eco aplicara su receta, fue seguramente porque la receta la aplicó un maestro. Y, a veces, ni siquiera esto garantiza el éxito. (Montero, 2010)

El éxito es la palabra clave. Publicar un bestseller es el objetivo. En La Tabla Esmeralda, hechos históricos tan complejos como la Segunda Guerra Mundial, el Holocausto, la deportación y el expolio de los judíos forman parte del arsenal empleado metódicamente para atraer al lector mediante una temática cada vez más popular y que vende bien. Tenía razón Vicente Luis Mora cuando en 2007 comparaba la literatura española con el mercado inmobiliario:

La narrativa española ha dejado de ser literatura para convertirse en mercado editorial. Y su crítica, la crítica oficial, suplementaria, ha dejado de ser crítica literaria, para convertirse en [...] propaganda. Añádanse los agentes literarios, y el terrible poder de los distribuidores, y lo tenemos todo. [...] Es una metáfora del sistema inmobiliario nacional, con promotores de obras (los escritores), inmobiliarias (editores), agentes (corredores de fincas), distribuidores (Hacienda...) y compradores, claro. (Mora, 2007: 8-9)

No cabe la menor duda de que la novela de Carla Montero es, desde luego, un exitoso producto comercial. Aparte del misterioso prólogo en la corte de Lorenzo de Médicis (Florencia, 1492), donde aparece brevemente el pintor Giorgio Barbarelli da Castelfranco (el llamado Giorgione), la novela combina dos niveles narrativos. El presente de la narración intradiegética y homodiegética, asumida por Ana 
García-Brest, se va alternando con otra narración, esta vez asumida por un narrador omnisciente, que concierne a los años 40 del siglo XX (septiembre de 1942 - abril de 1944). La historia de Ana García-Brest, española, historiadora de arte y novia de un rico empresario y coleccionista alemán, Konrad Köller, se entrelaza con el destino de Sarah Bauer, judía alsaciana y depositaria del secreto de su padre, a su vez perseguida por Georg von Bergheim, un oficial de las SS: ambas historias, aunque separadas temporalmente, tienen un desenlace en común.

La Tabla Esmeralda con sus 743 páginas de intrigas rocambolescas supo ganarse un público joven y entusiasta, tanto en España como en Polonia: los blogueros literarios polacos notaron que la parte contemporánea les parecía bastante esquematizada, pero juzgaron la parte histórica como apasionante y reveladora en muchos aspectos, sobre todo en cuanto a la realidad de París bajo la ocupación nazi. Para un lector especializado, sin embargo, esa realidad histórica donde, en abril de 1944, una judía se pasea tranquilamente por París con su bebé "en el cochecito de paseo" (p. 614) es tan poco verosímil como los amoríos entre una modesta historiadora de arte y un empresario alemán considerado "probablemente uno de los hombres más ricos de Europa" (p. 38), que en realidad es un neonazi y miembro de una sociedad secreta.

Es interesante notar que cada capítulo de la serie "histórica" va encabezado por una corta introducción, una suerte de resumen de los hechos históricos, que parece tomada de Wikipedia: es la versión pop de la Historia que se manifiesta en toda su plenitud. Por eso, me parece justificado resumir los rasgos característicos de la "novela coctelera" con una fuerte dominante histórica y llamarla una novela pophistórica:

1. La novela pophistórica es una novela cuyo referente está obviamente situado en el campo extraliterario, accesible a cualquier lector (Internet) y sin lugar a dudas.

2. La novela pophistórica se apoya en un conocimiento comúnmente compartido de la historia (Wikipedia), una serie de lugares comunes que reflejan las convicciones de la comunidad a la que pertenece el autor y sus lectores. 
3. La novela pophistórica tiene por objetivo ganar la popularidad entre sus lectores a través de un tema atrayente, una trama accesible, una visión del pasado exenta de vacilaciones que sirve de fondo para una intriga rocambolesca.

4. La novela pophistórica tiene como efecto "reforzar" las ideas compartidas y que sin embargo en muchas ocasiones suelen ser falsas o estereotipadas.

En vez de ofrecer una relectura del pasado desde los márgenes del poder, como lo prometen las novelas intrahistóricas, las novelas pophistóricas seducen sobre todo al público joven o poco especializado, consumidor de la cultura pop y adepto de los medios de comunicación de masas. Y, como observaba Mario Vargas Llosa criticando la civilización del espectáculo, la literatura light propaga el conformismo a través de la complacencia y la autosatisfacción, silenciando cualquier interrogación sobre el pasado y relegando la historia a su masticable versión pop.

En 2016 Carla Montero regresa con una nueva novela pophistórica, El invierno en tu rostro, seguramente más íntima y ambiciosa, con un epígrafe de Keats ("Para ti, que has sentido en tu rostro el invierno..."), inspirada en parte en su historia familiar durante y después de la Guerra Civil, pero también en las páginas olvidadas de la historia de Europa, como la última batalla de la Guerra Civil española que tuvo lugar el 10 de febrero de 1943, en la Unión Soviética: en la batalla de Krasny Bor, en una única jornada, murieron 2500 españoles de la División Azul. Desgraciadamente, otra vez, esa complicadísima intriga que incluye a los falangistas, los milicianos, los nazis, los judíos polacos, los espías y los maquis con aquel amplio fondo histórico que abarca desde Oviedo hasta Tánger, pasando por Lyon, París, Varsovia y Mestelewo, sirve básicamente para que los protagonistas, Lena y Guillén, tengan una vida amorosa tan intensa como imposible. Tal vez esté justificado subrayar que la novela pophistórica del siglo XXI reanude, en cierto modo, la tradición más pura de la novela histórica decimonónica, delegando a los personajes históricos a un segundo plano, para dibujar unas historias de amor y terror: algo que siempre satisface al público menos exigente. 


\section{Bibliografía}

ANGLADA, M.Á. (1994 [2007]), El violín de Auschwitz, trad. A. Hernández, Destino, Barcelona.

BARTHES, R. (1967), "Le discours de l'histoire", en: Le bruissement de la langue, Essais critiques IV, Paris, Seuil, pp. 163-177, https://doi. org/10.1177/053901846700600404.

BOBES NAVES, M.C. (1996), "Novela histórica femenina", en: Romera Castillo, J.N., Gutiérrez Carbajo F., García-Page M. (eds.), La novela histórica a finales del siglo XX, Visor, Madrid, pp. 39-54.

CIPLIJAUSKAITÉ, B. (1988), La novela femenina contemporánea: 19701985: hacia una tipología de la narración en primera persona, Anthropos, Barcelona.

CICHOCKA, M. (2016), Estrategias de la novela histórica contemporánea, Peter Lang, Bern.

DA CUNHA-GIABBAI, G. (1994), Mujer e historia: La narrativa de Ana Teresa Torres, Centro de Actividades Literarias El tigre, Caracas.

FÉNELON, F. (1976), Sursis pour l'orchestre, Stock, Paris.

FERNÁNDEZ-PRIETO, C. (2006), "La Historia en la novela histórica", Morales, J.J. (ed.), Reflexiones sobre la novela histórica, Fundación Fernando Quiñones y Universidad de Cádiz, Cádiz, pp. 165-184.

GARZÓN, J.I. (1977), “El Archivo Judaico del Franquismo”, Revista Raíces, 33, Madrid, pp. 57-60.

HAZAN, K. (2005), “Topographie-toponymie (II). Les lieux d'oubli. Sur les traces d'extermination", en: Des voix sous la cendre: manuscrits des Sonderkommandos d'Auschwitz-Birkenau, Calmann-Lévy, Paris, pp. 261-267.

HILBERG, R. (1961), The Destruction of the European Jews, W.H. Allen, London.

HIRSCH, M. (2008), "The Generation of Postmemory", Poetics Today 29, 1, Duke University Press, Durham, pp. 103-128.

HUTCHEON, L. (1989), "Historiographical Metafiction. Parody and the Intertextuality of History", en: Intertextuality and Contemporary American Fiction, O’Donnell, P., Con Davis, R. (eds.), The John Hopkins University Press, Baltimore and London, pp. 3-32.

LAKS, S. (1979), Gry oświęcimskie, Oficyna Poetów i Malarzy, Londyn. 
MONTERO, C. (2010), "Las modas literarias", 5.10, [on-line] https://carlamontero.wordpress.com/2010/10/05/las-modas-literarias/, 31.12.2016.

MONTERO, C. (2014 [2012]), La Tabla Esmeralda, Penguin Random House, Debolsillo, Barcelona.

MONTERO, C. (2016), El invierno en tu rostro, Barcelona, Plaza \& Janés.

MORA, V.L. (2007), La luz nueva. Singularidades en la narrativa española actual, Bartleby, Madrid.

PANKOWSKI, M. (2000), Z Auszwicu do Belsen. Przygody, Czytelnik, Warszawa.

REVERTE, J.M. (2010), "La lista de Franco para el Holocausto”, El País, 20.06.2010, [on-line] http://elpais.com/diario/2010/06/20/domingo/1277005953_850215.html, 31.12.2016.

RIVAS, L.M. (2000), La novela intrahistórica: tres miradas femeninas de la historia venezolana, Universidad de Carabobo, Valencia.

STROUMSA, J. (1998), Tu choisiras la vie: violoniste à Auschwitz, Éds. du Cerf, Paris.

UNAMUNO, M. de (1895 [1986]), En torno al casticismo, Alianza, Madrid. VARGAS LLOSA, M. (2009), "La civilización del espectáculo", Letras Libres, Editorial Vuelta, Madrid \& México D.F., [on-line] http://www.letraslibres.com/mexico-espana/la-civilizacion-del-espectaculo, 31.12.2016. WESSELING, E. (1991), Writing History as a Prophet: Postmodernist Innovations of the Historical Novel, Amsterdam, Philadelphia, J. Benjamins.

La Biblioteca de la Deportación, [on-line] https://bibliotecadeladeportacion. blogspot.com/p/catalogo.html, 10.02.2019. 